This item was submitted to Loughborough's Research Repository by the author.

Items in Figshare are protected by copyright, with all rights reserved, unless otherwise indicated.

\title{
Validity and reliability of an inertial sensor for wheelchair court sports performance
}

PLEASE CITE THE PUBLISHED VERSION

http://dx.doi.org/10.1123/jab.2013-0148

\section{PUBLISHER}

Human Kinetics

VERSION

AM (Accepted Manuscript)

\section{PUBLISHER STATEMENT}

This work is made available according to the conditions of the Creative Commons Attribution-NonCommercialNoDerivatives 4.0 International (CC BY-NC-ND 4.0) licence. Full details of this licence are available at: https://creativecommons.org/licenses/by-nc-nd/4.0/

\section{LICENCE}

CC BY-NC-ND 4.0

\section{REPOSITORY RECORD}

Mason, Barry S., James M. Rhodes, and Victoria L. Goosey-Tolfrey. 2019. "Validity and Reliability of an Inertial Sensor for Wheelchair Court Sports Performance". figshare. https://hdl.handle.net/2134/22650. 
2 JAB_2013_0148 R2

3

4 Validity and reliability of an inertial sensor for wheelchair court sports performance

5

6

$$
\text { Barry S. Mason, James M. Rhodes, and Victoria L. Goosey-Tolfrey }
$$

Peter Harrison Centre for Disability Sport, School of Sport, Exercise and Health Sciences, Loughborough University, Loughborough, Leicestershire, LE11 3TU, England, United Kingdom

10

11 Funding: UK Sport and the Peter Harrison Centre for Disability Sport provided the funding 12 for the current research.

13 Conflict of Interest Disclosure: No conflict of interest

14 Correspondence Address: Dr. Barry Mason, Peter Harrison Centre for Disability Sport, 15 School of Sport, Exercise and Health Sciences, Loughborough University, Loughborough, 16 Leicestershire, LE11 3TU, England, UK. 


\section{Abstract}

2 The purpose of the current study was to determine the validity and reliability of a gyroscope 3 sensor for assessing speed specific to athletes competing in the wheelchair court sports 4 (basketball, rugby and tennis). A wireless inertial sensor was attached to the axle of a sports 5 wheelchair. Over two separate sessions, the sensor was tested across a range of treadmill 6 speeds reflective of the court sports $\left(1.0 \mathrm{~m} \cdot \mathrm{s}^{-1}\right.$ to $\left.6.0 \mathrm{~m} \cdot \mathrm{s}^{-1}\right)$. At each test speed, $10 \mathrm{x} 10$ second 7 trials were recorded and were compared to the treadmill (criterion). A further session 8 explored the dynamic validity and reliability of the sensor during a sprinting task on a 9 wheelchair ergometer compared to high-speed video (criterion). During session one, the gyroscope marginally overestimated speed, whereas during session two these speeds were underestimated slightly. However, systematic bias and absolute random errors never exceeded $0.058 \mathrm{~m} \cdot \mathrm{s}^{-1}$ and $0.086 \mathrm{~m} \cdot \mathrm{s}^{-1}$ respectively, across both sessions. The gyroscope was also shown to be a reliable device with coefficients of variation (\% CV) never exceeding 0.9 at any speed. During maximal sprinting, the sensor also provided a valid representation of the peak speeds reached $(1.6 \% \mathrm{CV})$. Slight random errors in timing led to larger random errors in the detection of deceleration values. The results of this investigation have demonstrated that an inertial sensor developed for sports wheelchair applications provided a valid and reliable assessment of the speeds typically experienced by wheelchair athletes. As such this device will be a valuable monitoring tool for assessing aspects of linear wheelchair performance.

Keywords: inertial sensor, speed, wheelchair sports

Word Count: 2045 (technical note) 
Given the popularity of wheelchair basketball, rugby, and tennis (known collectively as the wheelchair court sports), the use of innovative technology has become a common feature of research investigations in order to further knowledge and advance performance levels in these sports. ${ }^{1,2}$ The challenge that faces researchers is to collect valid and reliable data about key performance indicators in a field-based environment, so that athletes and coaches are provided with the most meaningful information. Linear movements, such as the ability to accelerate, sprint and brake have been identified as key performance indicators in the wheelchair court sports. ${ }^{3}$ Therefore an accurate assessment of speed with regards to time is subsequently highly desirable in order to quantify these linear aspects of performance.

Numerous devices have been developed over the years to obtain indicators of speed in a wheelchair court sport environment. Coutts ${ }^{4}$ equipped a wheelchair with a cycle computer and two magnetic switches (at $180^{\circ}$ intervals), which was wired to a portable computer. More recently, a similar wireless device, called a miniaturised data logger (MDL), has been developed. ${ }^{5}$ The MDL, which attaches to the spokes of a wheelchair wheel, operates via three reed switches at $120^{\circ}$ intervals. The value of such a system is that it can be used to collect speed data during competition. ${ }^{6,7}$ Sporner et al. ${ }^{6}$ reported the mean speeds that wheelchair rugby $\left(1.33 \pm 0.25 \mathrm{~m} \cdot \mathrm{s}^{-1}\right)$ and wheelchair basketball players $\left(1.48 \pm 0.13 \mathrm{~m} \cdot \mathrm{s}^{-1}\right)$ obtain during competition. Sindall et al. ${ }^{7}$ revealed that these mean speeds were slightly lower during wheelchair tennis competition $\left(0.99 \pm 0.20 \mathrm{~m} \cdot \mathrm{s}^{-1}\right)$, yet importantly included information about the peak speeds reached $\left(3.18 \pm 0.41 \mathrm{~m} \cdot \mathrm{s}^{-1}\right)$. Peak speeds are important as they give an insight into the high intensity work that athletes are performing. Unfortunately, it is at these speeds where limitations have been associated with the aforementioned reed switch devices, with substantial errors reported at speeds $>2.5 \mathrm{~m} \cdot \mathrm{s}^{-1}$. . This is likely to be due to the fact that the MDL was originally developed for daily life wheelchair activities, as opposed to sporting performance. $^{5}$

Video analysis and image processing techniques have also been used to assess the speeds reached during wheelchair rugby ${ }^{9}$ and wheelchair tennis. ${ }^{10}$ Sarro et al. ${ }^{9}$ established similar mean speeds during wheelchair rugby $\left(1.22 \pm 0.21 \mathrm{~m} \cdot \mathrm{s}^{-1}\right)$ to the data collected via MDL. ${ }^{6}$ The mean $\left(0.93 \pm 0.21 \mathrm{~m} \cdot \mathrm{s}^{-1}\right)$ and peak speeds $\left(3.29 \pm 0.56 \mathrm{~m} \cdot \mathrm{s}^{-1}\right)$ observed by Filipcic and Filipcic ${ }^{10}$ during wheelchair tennis were also comparable to the MDL study. ${ }^{7}$ Although image processing techniques do allow for an accurate representation of the speeds recorded, 
they are heavily reliant on manual tracking, which can be an incredibly time consuming process. ${ }^{11}$ Although this may be suitable, from a match analysis perspective, athletes and coaches require much quicker feedback in a training environment, which is where a wheelchair 'Velocometer' has proven valuable. ${ }^{12}$ The 'Velocometer' cannot be used during competition, but can provide detailed feedback about important aspects of linear performance, such as initial acceleration and peak speeds. Subsequently, the 'Velocometer' has been used to compare the speed profiles of wheelchair tennis players pushing with and without a racket $^{13}$ and in various wheelchair configuration studies. ${ }^{14-16}$ Although extremely accurate ($0.00 \pm 0.41 \%$ error $)^{12}$ there are practical limitations associated with the wheelchair 'Velocometer' concerning mass, set-up and calibration time, which all need to be minimised when working with elite athletes.

The limitations associated with the 'Velocometer' has seen the introduction of microelectro-mechanical systems (MEMS) inertial sensors, including gyroscopes and accelerometers into a wheelchair sports environment. ${ }^{17-19}$ These are small and lightweight devices that can provide real-time feedback about key areas of sporting performance. It has been established that gyroscope sensors demonstrate acceptable errors for positioning and distance estimation during wheelchair propulsion. ${ }^{17-19} \mathrm{Xu}$ et al. ${ }^{17}$ and Chua et al. ${ }^{18}$ also suggested that they provided an accurate representation of speed. Unfortunately the speeds tested were not stated and appeared low in the context of wheelchair sports. The aim of the current investigation was subsequently to determine the validity of a gyroscope sensor across a range of speeds and activities specific to wheelchair court sports.

\section{Methods}

The current study was approved by the University’s local ethical advisory committee. A wireless inertial sensor, developed at Imperial College London, ${ }^{20-21}$ was attached to the right wheel of a court sport wheelchair (Bromakin Tennis XL, Bromakin Wheelchairs, Loughborough, UK). In brief the sensor (size $=20 \times 30 \times 17 \mathrm{~mm}^{3}$; mass $=10 \mathrm{~g}$ ) is equipped with three separate boards; a sensor board, a main board and a battery board (Figure 1). The sensor board incorporates a three-axis digital gyroscope (Invensense ITG-3200, California, USA) with a full scale range of $\pm 2000 \mathrm{deg} \cdot \mathrm{s}^{-1}$ and non-linearity of $0.2 \%$ of the full scale range. The main board uses the same microcontroller (TI MSP430) and radio module (Chipcon CC2420) as described by Pansiot et al. ${ }^{19}$. The sensor is powered by a lightweight 
1 lithium-polymer battery and transmits time-stamped data wirelessly at a sampling frequency 2 of approximately $50 \mathrm{~Hz}$ to a base unit connected to a laptop computer (Toshiba R700) 3 interfaced with the Body Sensor Network development kit. ${ }^{20-21}$ Raw data from the sensor was 4 then filtered using a Butterworth low-pass $2^{\text {nd }}$ order digital filter, with a $20 \mathrm{~Hz}$ cut-off 5 frequency. The sports wheelchair (0.65m main wheels; $20^{\circ}$ camber, 120 psi tyre pressure) 6 was attached to a motor driven treadmill (H/P Cosmos Saturn, Nussdorf-Traunstein, 7 Germany) and was loaded with $40 \mathrm{~kg}$ to improve stability during testing.

INSERT FIGURE 1 HERE

Initial testing took place over two identical sessions on separate days to assess the collection to obtain a measure of intrinsic bias and was recalibrated at the beginning of each speed increment. Calibration required the sensor to be in a stationary position on the wheelchair whilst a single baseline voltage measurement was recorded. The sensor was recalibrated prior to each speed increment. During both sessions, treadmill speeds were increased at $1.0 \mathrm{~m} \cdot \mathrm{s}^{-1}$ intervals ranging from 1.0 to $6.0 \mathrm{~m} \cdot \mathrm{s}^{-1}$. At each speed $10 \mathrm{x} 10$-seconds worth of data was collected from the gyroscope. The treadmill had previously been calibrated for accuracy across the range of speeds investigated using high-speed video analysis (Casio Exilim EX-F1, 300 frames $\cdot \mathrm{s}^{-1}$ ). The time taken to perform 10 revolutions at each speed increment (1.0 to $6.0 \mathrm{~m} \cdot \mathrm{s}^{-1}$ ) was recorded and analysed (Kinovea version 0.8.15, Bordeaux, France) to calculate mean speed. These speeds were shown to be within $0.4 \%$ of the treadmill speed selected across the range of speeds tested, implicating that the mean speed of the treadmill could be used as a reliable criterion variable. The mean speeds recorded by the treadmill were compared to those calculated by the sensor during each trial at each speed over both sessions.

A third separate testing session was performed to examine the dynamic validity and reliability of the sensor during maximal effort sprinting. The same sports wheelchair was fixed to a single roller wheelchair ergometer (Bromakin wheelchairs, Loughborough, UK). One able-bodied male participant (age $=29$ years; mass $=78.2 \mathrm{~kg}$ ) with previous experience of wheelchair propulsion was then required to sprint from a stationary position for five 
1 complete pushes and then bring the wheelchair back to a standstill as quickly as possible.

2 This was repeated five times. During each sprint data was captured using the sensor and was 3 also recorded using high-speed $(100 \mathrm{~Hz})$ video (Basler piA640-210gc). The video footage was analysed using SIMI Motion (Unterschleissheim, Germany) and the linear velocity of the wheel was calculated during each trial, which had been filtered using a Butterworth low-pass $2^{\text {nd }}$ order digital filter, with a $20 \mathrm{~Hz}$ cut-frequency to correspond to the sensors filtering method. The peak speeds over each of the first five pushes indicated by the sensor were compared to the speeds calculated from the video analysis. The time at which each of these peak speeds occurred was also examined. The acceleration values calculated from a standstill to the peak of the first push were also compared between both measures. Finally decelerations, standardised across trials as the rate of decrease in speed from $2.5-0.5 \mathrm{~m} \cdot \mathrm{s}^{-1}$, was calculated to assess braking performance.

Using the Statistical Package for the Social Sciences (SPSS version 19, Chicago, IL) the mean differences between the criterion (treadmill \& video) and sensor were calculated using a repeated measures analysis of variance (ANOVA) with 95\% confidence intervals (95\% CI) reported. Criterion validity was demonstrated using 95\% limits of agreement (LOA). The reliability of the inertial sensor was determined for each session by calculating the typical error, reported as coefficients of variation (\% CV).

During the treadmill trials, significant differences in mean speed existed between the sensor and treadmill at all test speeds, over both sessions (Table 1). During session 1, the sensor slightly overestimated speeds in relation to the treadmill. Systematic bias ranged from $-0.017 \mathrm{~m} \cdot \mathrm{s}^{-1}$ to $-0.036 \mathrm{~m} \cdot \mathrm{s}^{-1}$ and random errors ranged from $0.004 \mathrm{~m} \cdot \mathrm{s}^{-1}$ to $0.015 \mathrm{~m} \cdot \mathrm{s}^{-1}$. As revealed in Fig. 2 the magnitude of these errors was shown to increase significantly with speed ( $\mathrm{r}=-0.81 ; P<.05)$. The reliability of the sensor was $\leq 0.4 \% \mathrm{CV}$ across all speeds during session 1. During session 2, the sensor was shown to slightly underestimate the speed of the treadmill at all test speeds. Systematic bias ranged from $0.006 \mathrm{~m} \cdot \mathrm{s}^{-1}$ to $0.058 \mathrm{~m} \cdot \mathrm{s}^{-1}$, with random errors between $0.013 \mathrm{~m} \cdot \mathrm{s}^{-1}$ to $0.086 \mathrm{~m} \cdot \mathrm{s}^{-1}$ revealed during session 2 . The magnitude of absolute error was shown to significantly increase $(\mathrm{r}=0.95 ; P<.05)$ in absolute terms as a factor of speed (Figure 2). However, the reliability of the sensor was still $\leq 0.9 \% \mathrm{CV}$ across all test speeds. Figure 3 demonstrates a typical trace from the treadmill trials. 
INSERT FIGURE 3 HERE

7

8

During the sprinting trials, statistically significant differences existed between the sensor and the high-speed video data for each of the performance variables (Table 2). However, the 95\% LOA and CV demonstrated an acceptable level of agreement and reliability between the sensor and the video, particularly for the detection of peak speeds, as illustrated in Figure 4.

INSERT TABLE 2 HERE

INSERT FIGURE 4 HERE

\section{Discussion}

The aim of the current study was to examine the suitability of an inertial sensor for accurately and reliably measuring speed across a range of fixed speeds reflective of the wheelchair court sports and under dynamic sprinting tasks. Two separate sessions were selected to investigate the consistency of measurements elicited by the sensor during the fixed speed trials. The results demonstrated that during the first session, mean speeds were slightly greater and in the second session these were slightly lower compared with the criterion measure of speed. In addition to the different trends in over and underestimation between sessions, slight differences were also observed with regards to the accuracy of the sensor between these two sessions. Both sessions revealed an increase in the absolute 
differences between the sensor and treadmill as speed increased. These differences were less pronounced during session one and were extremely accurate with random errors of only $0.013 \mathrm{~m} \cdot \mathrm{s}^{-1}$ observed at the highest treadmill speed. Alternatively, the heteroscedasticity present in the data was more prominent during session two where random errors reached $0.086 \mathrm{~m} \cdot \mathrm{s}^{-1}$ at the highest treadmill speed. Despite the greater absolute errors at higher speeds, when expressed relatively, the gyroscope still provided a very accurate and reliable representation of speed, since coefficients of variation did not increase with speed and never exceeded $0.9 \% \mathrm{CV}$. Previous devices such as the MDL have reported increases in CV at speeds $>2.5 \mathrm{~m} \cdot \mathrm{s}^{-1}$, which is clearly not acceptable in wheelchair sports, where speeds far exceed this value. $^{8}$

Differences in sampling frequency were not responsible for the minor differences in accuracy between the fixed speed, treadmill sessions. The sampling frequency of the sensor is not entirely stable as it is governed by the bandwidth available to the whole system and was shown to fluctuate in the region of $45.8 \mathrm{~Hz}$ to $50.1 \mathrm{~Hz}$. However, these ranges were consistent over both sessions and correlations revealed that errors were not associated to sampling frequency $(\mathrm{r}=-0.055 ; P=0.554)$. Alternatively, it was possible that differences in absolute error and the tendency to over and underestimate speeds slightly between sessions may have resulted from the calibration procedure. Calibration requires the sensor to be stationary, whilst a measure of ground velocity is captured. ${ }^{19}$ It is possible that slight differences in gyroscope orientation during the calibration procedure could account for the changes in error and over/under estimation of speed. Subsequently, a great deal of care is recommended during the calibration procedure to ensure that the sensor is both stationary and in a similar orientation every time this process is repeated. Although calibration may have accounted for the differences in error, it must be reinforced that these errors were still extremely minimal and acceptable for the current application.

Under dynamic sprinting conditions the sensor demonstrated also an acceptable degree of accuracy and reliability for the detection of peak speeds with every push. However, the sensor introduced slight random errors when identifying the timing $( \pm 0.10 \mathrm{~s})$ and magnitude $\left(0.24 \mathrm{~m} \cdot \mathrm{s}^{-1}\right)$ of these peak speeds. These errors were not likely to be related to the technical specification of the sensor, as even at the $6 \mathrm{~m} \cdot \mathrm{s}^{-1}$ treadmill trials, the angular velocity of the sensor would have been operating at $1161 \mathrm{deg} \cdot \mathrm{s}^{-1}$, which is well within the full scale range of the device. Alternatively, these errors were more likely to be attributed to the magnitude and stability of the sampling frequency of the sensor, which at approximately 50 
$1 \mathrm{~Hz}$, may have been inadequate to determine rapid changes in movement during wheelchair

2 sprinting. The issues with timing would account for the slight underestimations in peak speeds and accelerations and the somewhat larger underestimations in deceleration values made by the sensor, whereby reliability also diminished, particularly during the assessment of braking performance (9. \% CV). Not only does the sampling frequency of the sensor vary between trials, it also fluctuates slightly within trials and although the data is time-stamped these fluctuations may have contributed to the error present in the data. Given the fact that synchronisation between the sensor and video trials was conducted manually at the start of each trial, it could be that a small amount of operator error was introduced into the results, which could also have contributed to the random error.

The current study has revealed that an inertial sensor, developed for wheelchair applications, provides an accurate measure of speed for linear wheelchair propulsion across a range of constant speeds specific to the wheelchair court sports. From a practical perspective this offers coaches a useful tool for monitoring and/or controlling workload during continuous fixed speed training drills. Given its accurate representation of speed and reliability within each session, the sensors primary function would be to assess the effectiveness of certain interventions that are conducted during the same session. Scientific interventions that explore athlete's performance in different wheelchair configurations or equipment for instance would benefit from the data provided. Since the sensor slightly underestimated speed during one session and overestimated speed during the following session, the use of the sensor for monitoring wheelchair athlete's performance longitudinally must be approached with caution. The current study has also revealed that the sensor is capable of accurately and reliably determining the peak speeds reached during sprinting and acceleration from a standstill, both of which are key indicators of mobility performance in the court sports. ${ }^{3}$ Therefore during these 'same-session' interventions the inertial sensor could be used to compare changes in peak speeds and accelerations between certain interventions, although the use of decelerations to compare braking performance between these interventions would not be advised. This was associated to the larger random errors present $\left( \pm 4.504 \mathrm{~m} \cdot \mathrm{s}^{2}\right)$.

It could be argued that a limitation associated with the current study was its failure to assess the performance of the sensor in the field environment, as this is the most ecologically valid environment for the wheelchair athlete. Although this is a worthy consideration for further investigation, an important facet of validity and reliability research is having a valid 
1 and reliable criterion measure to compare it to. Therefore the controlled conditions that a

2 laboratory environment creates maximises the validity of the criterion measures. For instance no complex techniques such as panning or tilting are required to obtain accurate measures of speed in this environment removing the introduction of additional errors. A slight limitation that may have been associated with the treadmill session was the use of high-speed video to calibrate the treadmill on a separate day to data collection. However, the treadmill was unlikely to drift within 24 hours, although if any, this effect was likely to have been extremely minimal.

To conclude, the current study revealed that an inertial sensor developed for wheelchairs provides an accurate and reliable measure of speed during linear wheelchair propulsion. In association with the practical benefits of being a small, lightweight device with minimal set-up and calibration time, the sensor is considered a valuable monitoring tool for athletic performance in wheelchair athletes.

\section{Acknowledgements}

The authors would like to thank UK Sport and Imperial College London for their assistance with the development of the inertial sensor and Bromakin Wheelchairs for the loan of their sports wheelchair.

1. Burkett B. Technology in Paralympic sport: performance enhancement or essential for performance? Br J Sports Med. 2010;44:215-220.

2. Keogh JWL. Paralympic sport: an emerging area for research and consultancy in sports biomechanics. Sport Biomech. 2011;10(3):234-253.

3. Vanlandewijck YC, Theisen D, Daly D. Wheelchair propulsion biomechanics: implications for wheelchair sports. Sports Med. 2001;31:339-367.

4. Coutts KD. Dynamic characteristics of a sport wheelchair. J Rehabil Res Dev. 1991;28(3):45-50.

5. Tolerico ML, Ding D, Cooper RA et al. Assessing mobility characteristics and activity levels of manual wheelchair users. J Rehabil Res Dev. 2007;44(4):561-572. 
6. Sporner ML, Garrett GG, Kelleher A, et al. Quantification of activity during wheelchair basketball and rugby at the National Veterans Wheelchair Games: a pilot study. Prosthet Orthot Int. 2009;33(3):210-217.

7. Sindall P, Lenton JP, Tolfrey K, et al. Wheelchair tennis match-play demands: effect of player rank and result. Int J Sports Physiol Perform. 2012;Epub ahead of print.

8. Sindall P, Lenton JP, Whytock K, et al. Criterion validity and accuracy of global positiong satellite and data logging devices for wheelchair tennis court movement. J Spinal Cord Med. 2012; In press.

9. Sarro KJ, Misuta MS, Burkett B, et al. Tracking of wheelchair rugby players in the 2008 Demolition Derby final. J Sports Sci. 2010;28(2):193-200.

10. Filipcic T, Filipcic A. Analysis of movement velocity and distance covered in wheelchair tennis. Kinesiol Slov. 2009;15(2):25-32.

11. Barris S, Button C. A review of vision-based motion analysis in sport. Sports Med. 2008;38(12):1025-1043.

12. Moss AD, Fowler NE, Tolfrey VL. A telemetry-based velocometer to measure wheelchair velocity. J Biomech. 2003;36:253-257.

13. Goosey-Tolfrey VL, Moss AD. Wheelchair velocity of tennis players during propulsion with and without the use of racquets. Adapt Phys Quart Exerc. 2005;22:291-301.

14. Mason BS, van der Woude LHV, Tolfrey K, et al. The effects of rear wheel camber on maximal effort mobility performance in wheelchair athletes. Int J Sports Med. 2012a;33:199-204.

15. Mason BS, van der Woude LHV, Lenton JP, et al. The effect of wheel size on mobility performance in wheelchair athletes. Int J Sports Med. 2012b;33:807-812.

16. Goosey-Tolfrey VL, Mason B, Burkett B. The role of the velocometer as an innovative tool for Paralympic coaches to understand wheelchair sporting training and interventions to help optimise performance. Sports Technol. 2012;5(1-2):20-28.

17. Xu H, Chua JC, Burton M, et al. Development of low cost on-board velocity and position measurement system for wheelchair sports. Procedia Eng. 2010;2:3121-3126.

18. Chua JJC, Fuss FK, Subic A. Evaluation of different gyroscope sensors for smart wheelchair applications. Procedia Eng. 2011;13:519-524.

19. Pansiot J, Zhang Z, Lo B, et al. WISDOM: wheelchair inertial sensors for displacement and orientation monitoring. Meas Sci Technol. 2011;22(10):1-9.

20. Lo B, Thiemjarus S, King R, et al. Body sensor network: a wireless sensor platform for pervasive healthcare monitoring. In $3^{\text {rd }}$ International Conference on Pervasive Computing. 2005;13:13-18. 
1 21. Ellul J, Lo B, Yang GZ. The BSNOS platform: a body sensor networks targeted operating 2 3 system and toolset. In Proceedings of SENSORCOMM 2011, Nice, France Aug 2127. 
2 Figure 1 - The inertial based sensor and its positioning on the wheel.

3 Figure 2 - The mean differences between the sensor and treadmill speed during a) session 4 one; and b) session two. Error bars represent 95\% LOA.

5 Figure 3 - A typical speed trace of the inertial sensor during a $2 \mathrm{~m} \cdot \mathrm{s}^{-1}$ treadmill trial

6 Figure 4 - A comparison of a typical speed trace produced by the inertial sensor and the 7 high-speed video during the sprinting trials.

8

\section{Tables}


1 Table 1 The validity and reliability of the inertial sensor across the range of speeds and sessions in comparison to the treadmill. Speeds displayed are means 2 ( \pm SD).

\begin{tabular}{|c|c|c|c|c|c|c|c|c|c|c|}
\hline \multicolumn{6}{|c|}{ Session 1} & \multicolumn{5}{|c|}{ Session 2} \\
\hline $\begin{array}{l}\text { Speed } \\
\left(\mathrm{m} \cdot \mathrm{s}^{-1}\right)\end{array}$ & $\begin{array}{c}\text { Treadmill } \\
\left(\mathrm{m} \cdot \mathrm{s}^{-1}\right)\end{array}$ & $\begin{array}{l}\text { Sensor } \\
\left(\mathrm{m} \cdot \mathrm{s}^{-1}\right)\end{array}$ & $\begin{array}{c}95 \% \mathrm{CI} \\
\left(\mathrm{m} \cdot \mathrm{s}^{-1}\right)\end{array}$ & $\begin{array}{c}95 \% \text { LOA } \\
\left(\mathrm{m} \cdot \mathrm{s}^{-1}\right)\end{array}$ & $\% \mathrm{CV}$ & $\begin{array}{c}\text { Treadmill } \\
\left(\mathrm{m} \cdot \mathrm{s}^{-1}\right)\end{array}$ & $\begin{array}{l}\text { Sensor } \\
\left(\mathrm{m} \cdot \mathrm{s}^{-1}\right)\end{array}$ & $\begin{array}{c}95 \% \mathrm{CI} \\
\left(\mathrm{m} \cdot \mathrm{s}^{-1}\right)\end{array}$ & $\begin{array}{c}95 \% \text { LOA } \\
\left(\mathrm{m} \cdot \mathrm{s}^{-1}\right)\end{array}$ & $\% \mathrm{CV}$ \\
\hline \multirow[t]{2}{*}{1} & 1.02 & $1.03^{*}$ & $1.025-1.031$ & $-0.017 \pm 0.004$ & 0.4 & 1.02 & $1.01^{*}$ & $1.018-1.021$ & $0.006 \pm 0.013$ & 0.7 \\
\hline & $(0.01)$ & $(0.00)$ & & & & $(0.00)$ & $(0.00)$ & & & \\
\hline \multirow[t]{2}{*}{2} & 1.99 & $1.99 *$ & $1.987-1.995$ & $-0.017 \pm 0.005$ & 0.2 & 1.96 & $1.94 *$ & $1.940-1.947$ & $0.006 \pm 0.028$ & 0.6 \\
\hline & $(0.01)$ & $(0.01)$ & & & & $(0.00)$ & $(0.00)$ & & & \\
\hline \multirow[t]{2}{*}{3} & 2.97 & $2.98 *$ & $2.979-2.983$ & $-0.018 \pm 0.004$ & 0.3 & 2.99 & $2.97 *$ & $2.959-2.971$ & $0.009 \pm 0.039$ & 0.6 \\
\hline & $(0.00)$ & $(0.00)$ & & & & $(0.00)$ & $(0.01)$ & & & \\
\hline \multirow[t]{2}{*}{4} & 3.97 & $3.99 *$ & $3.982-3.992$ & $-0.027 \pm 0.009$ & 0.3 & 3.98 & $3.94 *$ & $3.937-3.943$ & $0.022 \pm 0.052$ & 0.7 \\
\hline & $(0.00)$ & $(0.01)$ & & & & $(0.00)$ & $(0.00)$ & & & \\
\hline \multirow[t]{2}{*}{5} & 5.01 & $5.04^{*}$ & $5.023-5.040$ & $-0.036 \pm 0.015$ & 0.4 & 5.02 & $4.97 *$ & $4.965-4.975$ & $0.038 \pm 0.068$ & 0.8 \\
\hline & $(0.00)$ & $(0.01)$ & & & & $(0.00)$ & $(0.01)$ & & & \\
\hline \multirow[t]{2}{*}{6} & 5.97 & $5.99 *$ & $5.985-5.991$ & $-0.031 \pm 0.013$ & 0.3 & 5.99 & $5.92 *$ & $5.914-5.923$ & $0.058 \pm 0.086$ & 0.9 \\
\hline & $(0.01)$ & $(0.00)$ & & & & $(0.00)$ & $(0.01)$ & & & \\
\hline
\end{tabular}

3

$4 \quad$ *significant difference to treadmill speed 
1 Table 2 . The validity and reliability of the inertial sensor during wheelchair sprinting.

\begin{tabular}{ccccc}
\hline & Video & Sensor & $95 \%$ LOA & $\%$ CV \\
\hline Peak speeds at each push $\left(\mathrm{m} \cdot \mathrm{s}^{-1}\right)$ & & & & \\
Timing of peak speeds $(\mathrm{s})$ & & $*$ & $-0.092 \pm 0.241$ & 2.7 \\
Acceleration from a standstill $\left(\mathrm{m} \cdot \mathrm{s}^{2}\right)$ & $2.68(0.23)$ & $2.60^{*}(0.20)$ & $-0.151 \pm 0.315$ & 2.5 \\
Deceleration $\left(\mathrm{m} \cdot \mathrm{s}^{2}\right)$ & $9.9(1.3)$ & $8.8^{*}(1.3)$ & $-2.252 \pm 4.504$ & 9.0 \\
\hline
\end{tabular}

2

3 *significant difference to video 

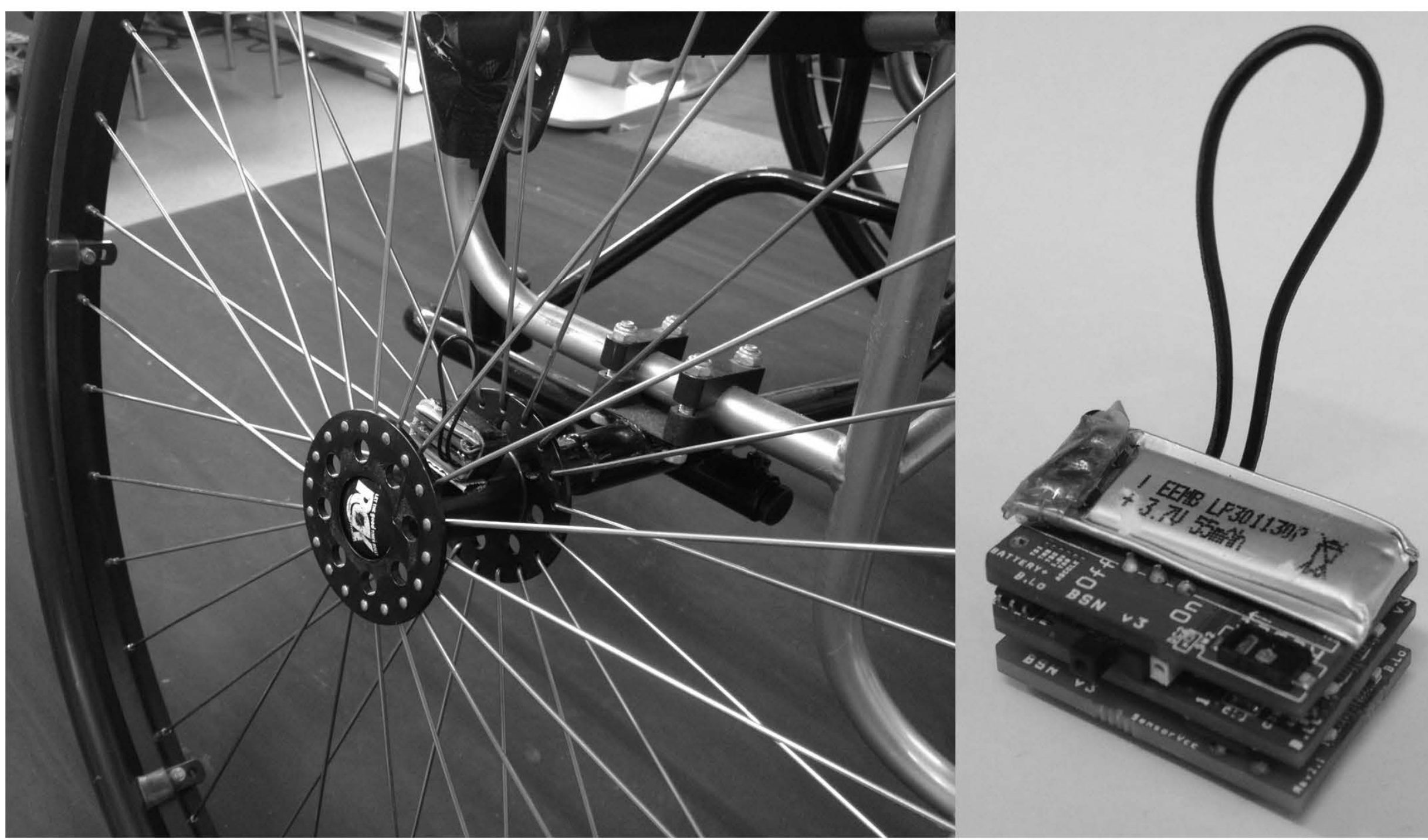

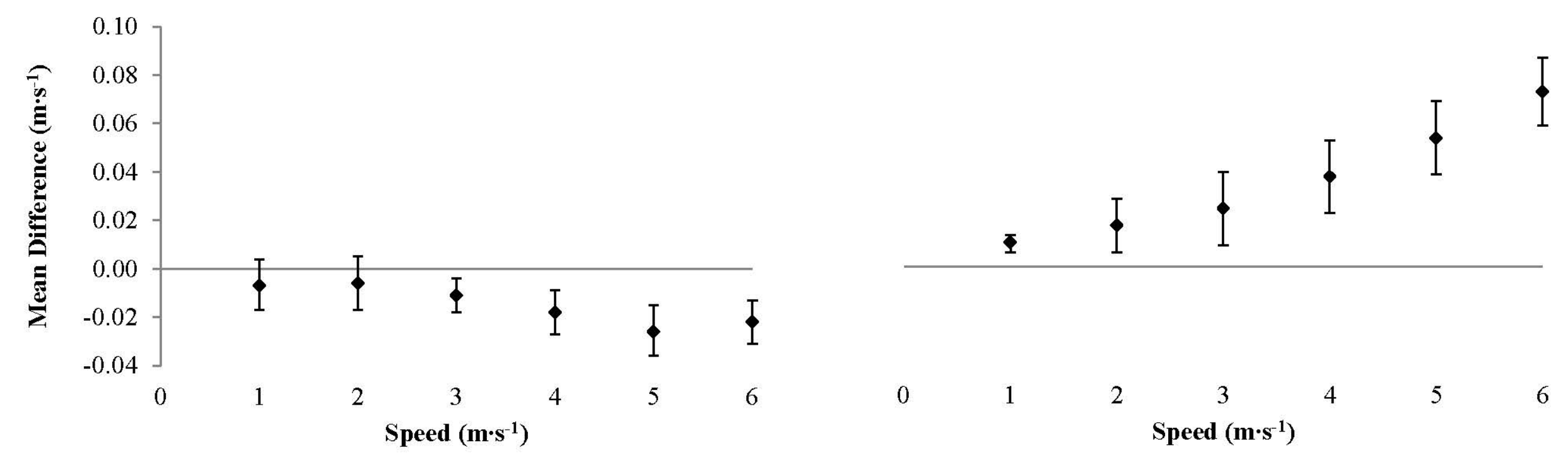


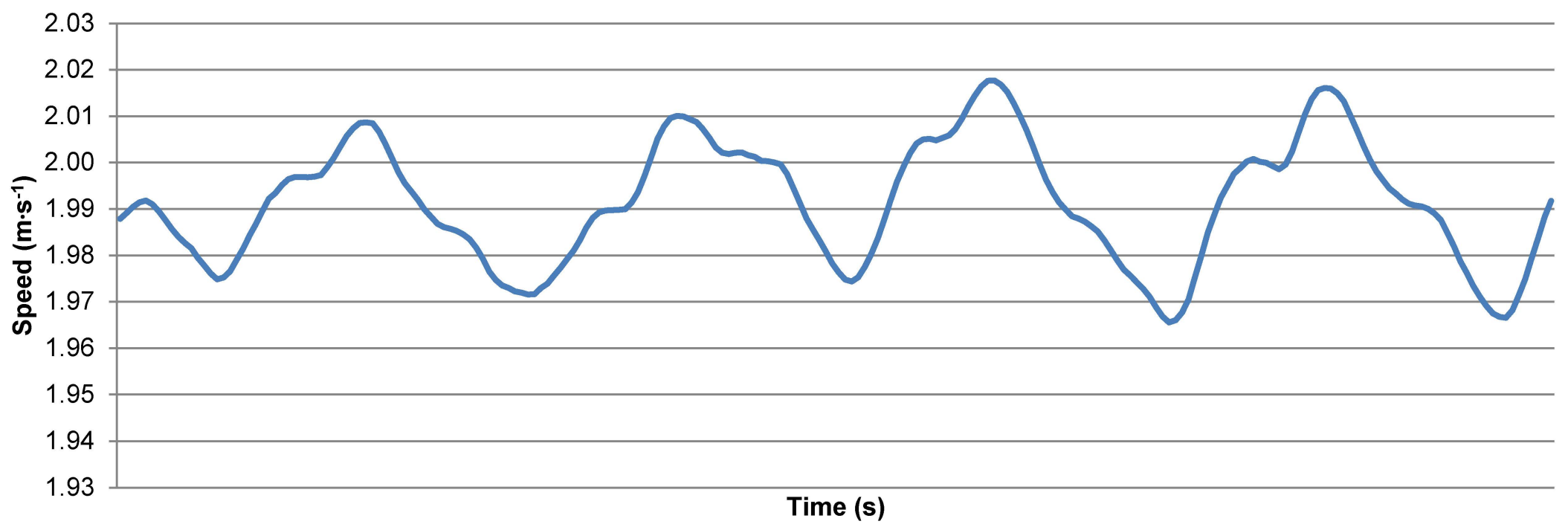




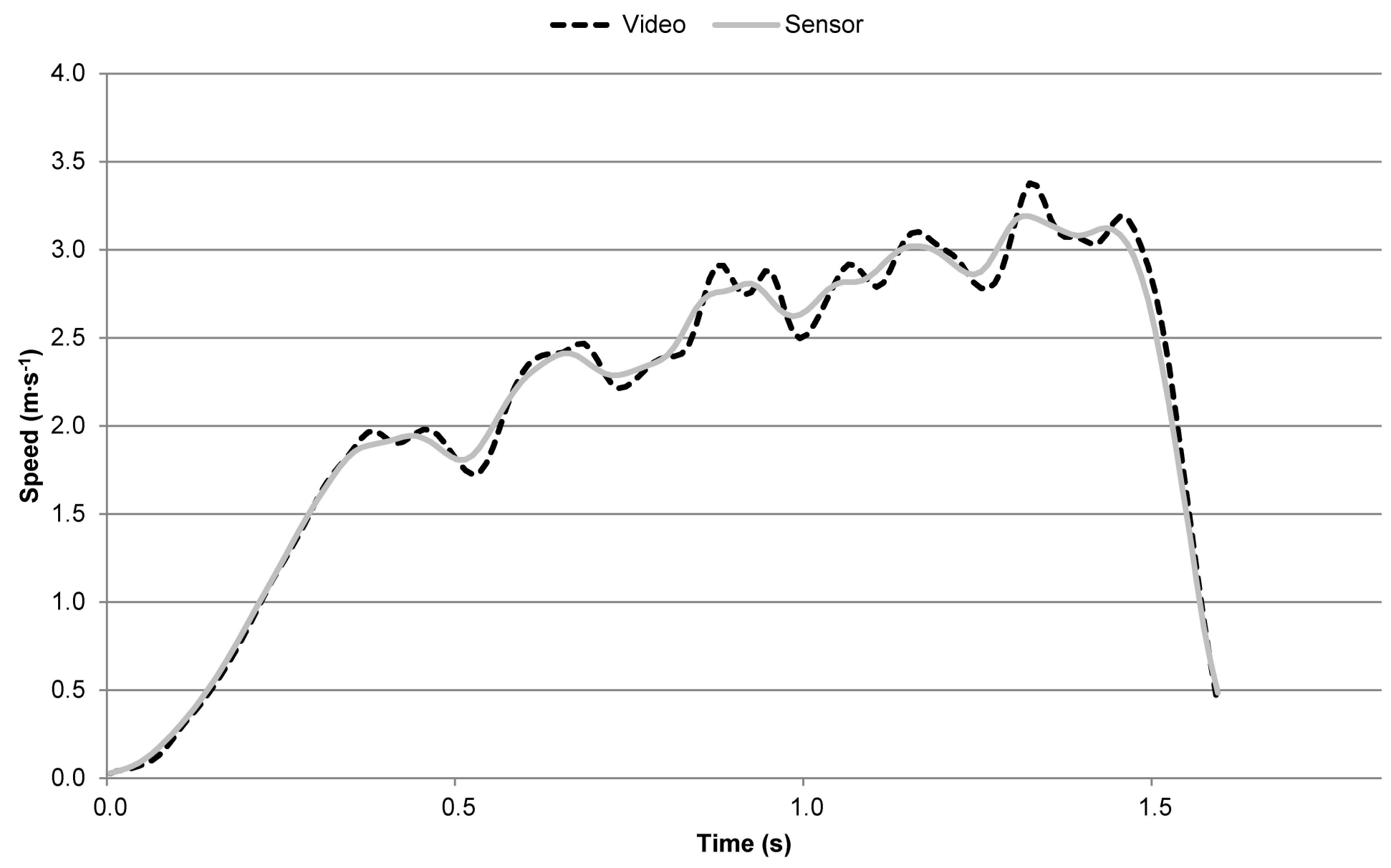

